\title{
Integrated Wireless Monitoring and Control System in Reverse Osmosis Membrane Desalination Plants
}

\author{
Ahmad Al Haji ${ }^{\text {a }}$ and Ali Al Odwani \\ Kuwait Institute for Scientific Research/Water Research Center, Kuwait, Kuwait
}

\begin{abstract}
The operational processes of the Reverse Osmosis (RO) membrane desalination plants require continuous monitoring through the constant attendance of operators to ensure proper productivity and minimize downtime and prevent membrane failure. Therefore, the plant must be equipped with a control system that monitors and controls the operational variables. Monitoring and controlling the affecting parameters are critical to the evaluation of the performance of the desalination plant, which will help the operator find and resolve problems immediately. Therefore, this paper was aimed at developing an RO unit by utilizing a wireless sensor network (WSN) system. Hence, an RO pilot plant with a feed capacity of $1.2 \mathrm{~m} 3 / \mathrm{h}$ was utilized, commissioned, and tested in Kuwait to assess and verify the performance of the integrated WSN in RO membrane desalination system. The investigated system allowed the operators to remotely monitor the operational process of the RO system. The operational data were smoothly recorded and monitored. Furthermore, the technical problems were immediately determined, which reduced the time and effort in rectifying the technical problems relevant to the RO performance. The manpower requirements of such treatment system were dramatically reduced by about $50 \%$. Based on a comparison between manual and wireless monitoring operational processes, the availability of the integrated RO unit with a wireless monitoring was increased by $10 \%$
\end{abstract}

\section{Introduction}

Desalination by seawater reverse osmosis is considered one of the most viable solutions for future sustainability of Kuwait's freshwater supply. This fact is well recognized by the Government of Kuwait and by the Kuwait Institute for Scientific ${ }^{1}$ Research (KISR). The magnitude of the challenges facing Kuwait in relation to water cannot be overstated. Natural freshwater resources are very limited and are being depleted; freshwater demand is rising; the costs and energy needed for desalination are among the largest items in the government's expenditure [1].

RO technology has proven to be reliable and is a successful process under the prevalent conditions of the region [2]. The process does not require heat or a change of phase to separate dissolved salts from saline solutions. High pressure is used to separate freshwater from saline feed water through a semipermeable membrane. Since there is no change in phase, less energy is required to desalt the feed water. The driving pressure required for separation is proportional to the total dissolved solids (TDS) concentration in the feed water. A control valve

\footnotetext{
${ }^{a}$ Corresponding author:akhaji@kisr.edu.kw
}

normally controls the discharge rate; without the control, the pressurized feed water would continue to increase in salt concentration, and could cause major problems including precipitation and high osmotic pressures across the membranes. The brine discharge rate depends on several factors including feed conditions and membrane type. All RO systems are similar as they all consist of four basic sections namely, pretreatment, high-pressure pump, membrane assembly, and posttreatment [3] (Fig.1)

Automation is now perceived as a major factor in determining desalination unit performance and has become a significant part of all desalination process. Automation is important to reduce failures and minimize manpower requirements. Properly designed and executed automation, virtual instrumentations, and data acquisition systems (DAS) should ensure safe and economical operation of RO units by providing early warning signals, indicating when process parameters are approaching critical values.

Therefore, a recently constructed prototype RO unit suitable for display and training purposes has been selected for this improvement. The prototype unit has been constructed to contribute directly to the enhancement, awareness and understanding of the technology [4]. However, as control systems are also 
considered to be vital to the automated operation and monitoring of complex technical processes such as desalination, it was decided that the previous work should be completed with the construction of a wireless monitoring and control system.

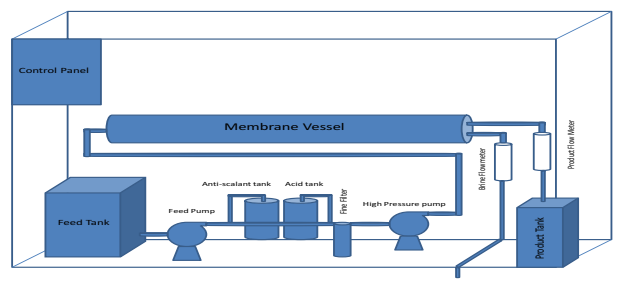

Figure 1. Layout of the reverse osmosis (RO) unit.

\section{Objective}

The main goal of this paper was to develop and construct a wireless sensor network system (WSN), which would free the operator from the confines of wired infrastructure and could offer more insight into the overall asset, preventing downtime and reducing maintenance.

\section{Experiment Setup Description}

A control system was installed into prototype RO unit which has a capacity of $1200 \mathrm{l} / \mathrm{h}$, as shown in Fig 1 . The components required for the assembly of the control system were acquired from National Instruments. The equipment and instrumentation needed for implementation of a wireless sensor network are as follows:

- National instruments eathernet gateaway(NI WSN9791) (is a pass-through device that must be connected to a host system. This gateway has a 2.4 $\mathrm{GHz}$, IEEE 802.15.4 radio to collect measurement data from the sensor network and a 10/100 Mbit/s Ethernet port to provide flexible connectivity to a Windows or LabVIEW Real-Time host controller.)

- Programmable nodes (NI WSN- 3202) which offers four $\pm 10 \mathrm{~V}$ analog input channels with selectable input ranges and four bidirectional digital channels that can be programmed for event detection or local control. The 18-position screw-terminal connector delivers direct connectivity to sensors and offers a 12$\mathrm{V}, 20-\mathrm{mA}$ sensor power output that can be used to drive sensors that require external power.

- $\mathrm{pH}$ sensor $-\mathrm{S} 8000 \mathrm{pH}$ electrodes

- Pressure sensor- PWLX04S

- Flow meter- badger Series 200 Meter Transducer

The installed system includes sensors that are used to measure critical operational parameters such as $\mathrm{pH}$, pressure, and flow rate. It also contains an actuation system that enables direct influence over the process, such as the option of measuring a given variable. The communication structure is responsible for transferring data safely from the unit to the main control station wirelessly via a WSN, as shown in Fig. 2

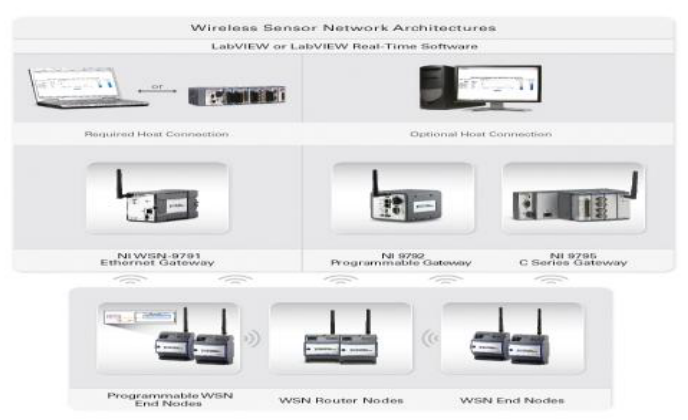

Figure 2. Wireless sensor network architecture

\subsection{Wiring Connections}

- Wired Connection to the pH Sensor: The connection is between the $\mathrm{S} 8000 \mathrm{pH}$ electrodes and the WSN-3202 node. The connection required a unity gain amplifier (a battery-powered EM800) to reduce the output impedance of the sensor, and to produce a signal of $59 \mathrm{mV} / \mathrm{pH}$.

- Wired Connection to the Pressure Sensor: A model PWLX04S compact pressure sensor was installed at the appropriate pressure-reading point. The sensor was supplied with electricity from an external source, because it required 12 to $30 \mathrm{~V}$ of direct current (DC) with a $125-\mathrm{mA}$ current.

- Wired Connection to the Flow Sensor: A badger Series 200 Meter Transducer was used for the flow sensor. The sensor needed stimulus from an external source, for which the sensor power in the node was used. The use of a $10^{-} \mathrm{k} \Omega$ or greater resistor was recommended to limit the current drawn from the node and to extend the battery's lifetime. In addition to the current limiter, a shield was connected to the node to decrease the noise in the signal.

\subsection{Programming the Nodes}

- Programming of the Sensorex S8000 pH Electrode Using LabVIEW: The LabVIEW Project Explorer window reads data from the WSN node. It then measures the voltage differential from the sensor's (Sensorex S8000) pH electrode. For initial start-up, it was necessary to configure the properties of the node. Then, under the channels tab, all of the channels had to be configured for Type 0 , i.e., analog input with an input range of -0.5 to $0.5 \mathrm{~V}$. In addition, interval hardware configuration setting had to be set appropriately to collect readings at the required frequency, i.e., one reading per hour [5].

In order to read the Sensorex S8000's data with LabVIEW, it was important to see the current values of the shared variables available from the WSN3202. Therefore, after checking the analog input channels to which the Sensorex S8000 was connected, the analog signals were scaled to the $\mathrm{pH}$. To obtain accurate readings, the sensor's measurements had to be calibrated as per the user manual. Hence, the 
output of the $\mathrm{pH}$ sensor was calibrated to $0 \mathrm{~V}$ at $\mathrm{pH} 7$, and to change with $\mathrm{pH}$ by $59.2 \mathrm{mV}$ per unit of $\mathrm{pH}$.

- Programming of the Wireless Sensor Network for Use with the (PW Pressure Transducer) Sensor Using LabVIEW: LabVIEW eased the programming of the PW series sensor applications. First, the input channels for the WSN-3202 were set between -10 and $10 \mathrm{~V}$, to comply with the PWLX04S's output voltage range of 0 to $10 \mathrm{~V}$. Then, the sensor powering in the channel attributes section of the WSN-3202 was enabled. The attribute was set to 'Sensor Excitation', and the value was set to $25 \mathrm{~ms}$. Each input and output variable on the voltage node had a corresponding variable in LabVIEW. The analog input variable for the pressure channel was dragged onto the block diagram. The variable output voltage values, which range between 0 and $10 \mathrm{~V}$, needed to be scaled to the appropriate values.

- Programming of LabVIEW for the Wireless Sensor Network for Use with the Badger 200 Meter Transducers: To measure flow rates, a Badger meter transducer was installed. When the impeller is stationary, the WSN node reads a value of $12 \mathrm{~V}$. However, when the impeller rotates, the nonmagnetic pick-up shorts the high lead wire to ground to a value of $5 \mathrm{~ms}$. Digital input and output (DIO) notifications and the LabVIEW WSN Module are normally used to find the rising edges of the pulse and the occurrence of the signal. If a digital input task was combined with LabVIEW for WSN, sample rates could reach around $1 \mathrm{kHz}$. The frequency of the signal is found after noticing the difference in time between the two stored codes, which can then be read on the WSN's published analog input and output (AIO). From there, the volumetric flow rate of the system can be calculated.

\section{Results and Discussion}

Upon the completion of the wiring and the programming, the connections were verified through testing to determine whether or not an output reading was showing on the operator's laptop. The programming was also checked to make sure that the readings of measurements on the laptop were the original data, and that the sensors were enquiring the correct data. This was done by comparing the system's readings against the manual readings taken at the sampling point for cross checking.

- $\mathbf{p H}$ readings: The average $\mathrm{pH}$ measurements for feed and product measured manually were 7.1 and 6.8 respectively, as shown in fig. 3. The newly installed WSN provided measurements that were very close to the manual measurements. The feed $\mathrm{pH}$ showed slight fluctuation around 7.1865 with the highest measurement, not exceeding 7.188 and the lowest measurement not dropping below 7.1855. The product $\mathrm{pH}$ fluctuate around 7.173 , reaching as high as 7.174 and dropping as low as 7.172 . The product $\mathrm{pH}$ was $3 \%$ off the manual measurement. The slight fluctuation in the measurements indicated the smooth operation of the unit and the stable quality of both the feed and the product water. An image captured of the $\mathrm{pH}$ screen is given in fig. 4 .

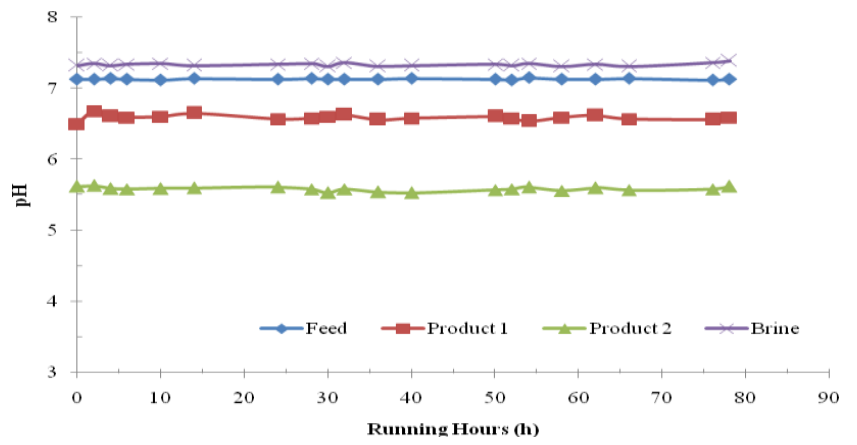

Figure 3. $\mathrm{pH}$ of feed, products, and brine versus time.

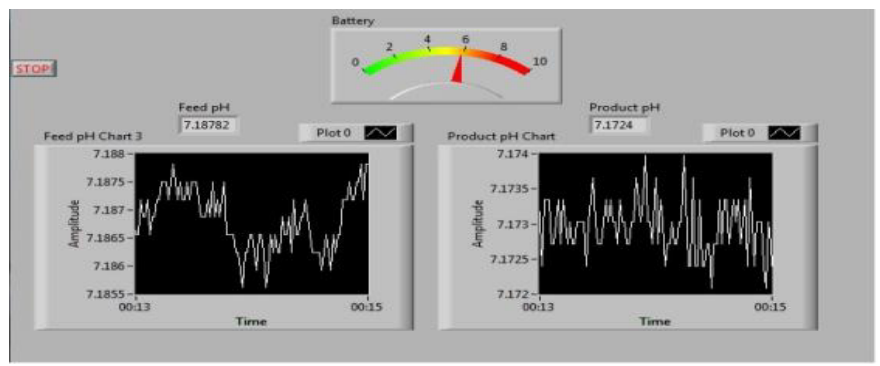

Figure 4. Image of the $\mathrm{pH}$ measurement screen.

- Pressure readings: The difference between the inlet and outlet pressures across the membrane is a key indication of how the membrane is performing. As the differential pressure across the membrane increases, the membrane may face some sort of blockage. For clean feed water and an excellently performing membrane, the difference in pressure ranges between 0.5 and 1.5 bars. If there is a sudden increase in the pressure difference, then the brine discharge valve might be not working properly or salts may have accumulated. If such a situation is not resolved by the operator, the sudden increase in the inlet pressure could harm the pump and the membranes if no pressure safety interlock is available. Hence, controlling and monitoring the pressure are very important for the safety of the equipment and staff. The manual pressure measurements recorded the difference in pressure is 1 bar, as shown in fig.5, while the automatic pressure measurements fluctuated around within 0.01 bars to 0.19 bars throughout the experiment. No major increase or decrease in the pressure was observed indicating proper functioning of the equipment and smooth operation of the system as shown in figure 6.

- Flow Readings: The volumetric flow meters were installed into the RO unit measure product and brine flow rates. This new system provided an extra tool for calculating the flow rate of the feed entering the membrane. Manual measurements of the feed flow rate were based on the sum of the brine and product flow rates as shown in fig.7. The new flow meter values confirmed the calculated ones. Figure 8 shows that the product flow rate fluctuated around $400 \mathrm{l} / \mathrm{h}$; the brine flow rate fluctuated around $800 \mathrm{l} / \mathrm{h}$, and the 
feed flow rate was around $1200 \mathrm{l} / \mathrm{h}$. Since the feed concentration is typical Arabian Gulf seawater, the recovery of a good membrane is around $35 \%$. This new system provided sufficient information to calculate the recovery rate of the system, which was more than $33 \%$.

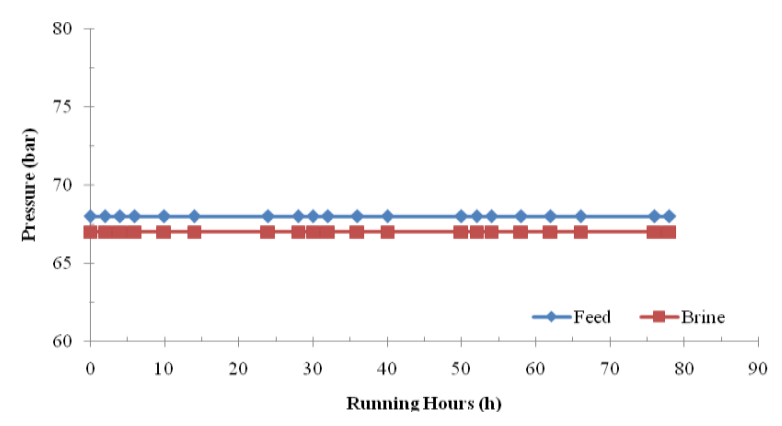

Figure 5. Reverse Osmosis feed and brine pressures versus time

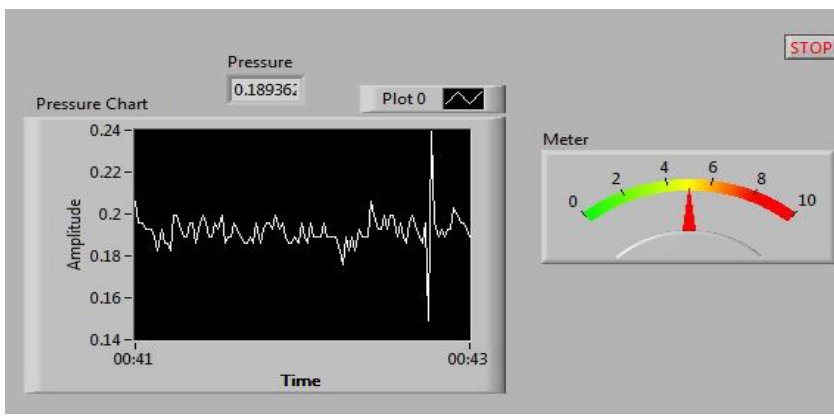

Fig. 6. Image of the differential pressure measurement screen.

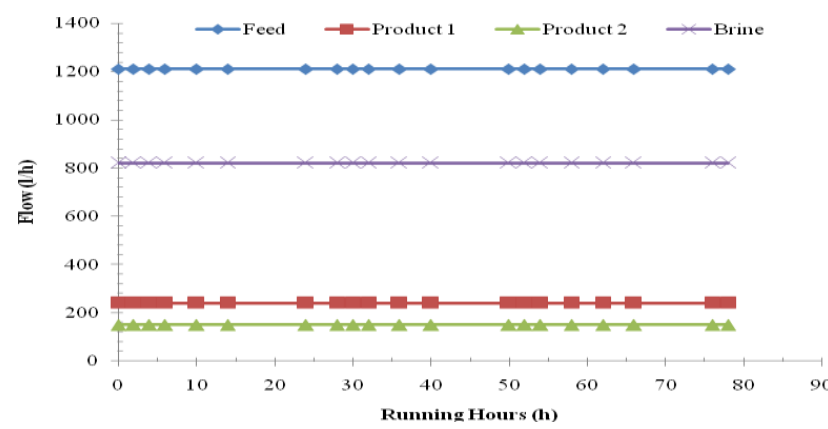

Figure 7. Flow rates of feed, products, and brine versus time.

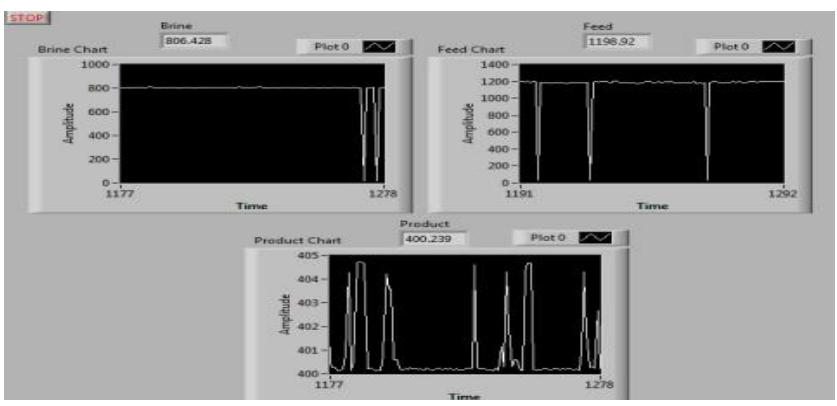

Figure 8. Image of the flow measurement screen
- System availability: Availability is defines as the probability of finding any system in the operating state at any given time. Availability depends on the effort made to maintain the equipment ahead of failure, through the help of early warning signals. The system's availability was calculated for the commissioning period, which was for 72 -hours. The shutdown time of the RO system amounted to $1.5 \mathrm{~h}$, while the total hours of operation were $72 \mathrm{~h}$. The availability of the RO system was calculated as follows:

$$
\begin{aligned}
& \text { Availability }=\frac{\text { Total Run Time }}{\text { Total Run Time+Total Downtime }} \\
& \text { Thus, } \\
& \text { Availability }=\frac{72}{73.5}=98 \%
\end{aligned}
$$

\section{Conclusion and Recommendation}

This paper illustrated the wireless transfer of data acquisition through to allow operators to monitor operation and confirm manual measurements. The sensors installed allow the operators to monitor the operation of the process remotely and to attain required operational data in a more professional format. The operator can easily review the performance of the unit in operation at his/her convenience. Problems can also be traced easily in real-time as they occur. This can save time and effort in rectifying such problems. For future work, more control parameters will be added such as conductivity, silt density index, and installing automatic valves to fully automate the process using wireless sensor network, which can provide key features such as maximized availability, reduced downtime, minimized manpower requirements, and trouble-free operation which would appeal to end users and would enable them to reduce operating costs.

\section{References}

1. El-Sayed, E.; M. Abdel-Jawad; Y. Al-Wazzan; A. Al-Odwani; G. Al-Nuwaibit; M. Al- Tabtabaei; S. Bou-Hamad; O. Al-Sayegh; M. Safar; M. Salman; A. Al-Saffar; M. Al-Musallam; and A. Al-Sairafi. 2010. Assessment of electrical power generation and water desalination plants. Kuwait Institute for Scientific Research, Report No. KISR 10404, Kuwait.

2. El-Sayed, E.; M. Abdel-Jawad; O. Al-Sayegh; Y. Al-Wazzan; A. Al-Odwani; G. Al-Nuwaibit and S. Bou-Hamad. 2009b. Initial status review and development of work program for assessment of power and desalination plants in Kuwait. Kuwait Institute for Scientific Research, Report No. KISR 9630, Kuwait.

3. Al-Odwani, A.; S. Bou-Hamad; F. Jabsheh; M. AlTabtabaei; A. Al-Sairafi; A. Al-Saffar; A. Al-Mesri; and M. Al-Rughaib. 2011. Long-term prototype study for the operation, production, and quality control of Kadhmah water bottling plant. Kuwait 
Institute for Scientific Research, Report No. KISR 10625, Kuwait.

4. Al-Mesri, A, and A. Al-Haji. 2012. Construction of a mobile seawater reverse osmosis unit. Kuwait institute for Scientific Research, Report No. KISR 11054, Kuwait.

5. NI. 2009. Using the Sensorex $58000 \mathrm{pH}$ electrode with NI Wireless sensor networks (WSN). National Instruments, n.p. Available at NI-Tutorial-9955en.pdf (Accessed on June 13, 2013).

6. Abdel-Jawad, M., and S. Ibrahim. 1994. Beachwell seawater intake as feed for an RO desalting system. Desalination 99(2):57-71. 